\title{
Palliative-D - Can vitamin D supplementation reduce symptom burden for palliative cancer patients?
}

Maria Helde Frankling (MD) ${ }^{12}$, Caritha Klasson (Reg Nurse) ${ }^{1}$, Marie Nordström (MD, PhD) ${ }^{3}$, Carina Sandberg (Reg Nurse) ${ }^{3}$, Jenny Bergqvist (MD, PhD) 45, Linda Björkhem Bergman (MD, PhD, Assoc Prof) 12

${ }^{1}$ ASIH Stockholm Södra, Långbro Park, Bergtallsvägen 12, 2559 Älvsjö, 2 Karolinska Institutet, Department of Neurobiology, Care Sciences and Society (NVS), Division of Clinical Geriatrics, ${ }^{3}$ Stockholms sjukhem, ${ }^{4}$ Karolinska Institutet, Department of Oncology-Pathology, ${ }^{5}$ Breast Centre, Departmentt of Surgery, Capio S:t Görans Hospital

\section{Aim: To perform a randomized, double-blind, placebo controlled, multi-center trial to test the hypothesis that vitamin-D supplementation to palliative cancer reduces pain, infections and fatigue, and improves self-reported quality of life.}

\section{Background}

Vitamin D supplementation to patients with vitamin $\mathrm{D}$ deficiency may have beneficial effects on pain, infections, and well-being without any significant side effects.

Vitamin D status is measured as S-25-OHD, and levels below 50 $\mathrm{nmol} / \mathrm{L}$ are considered to be insufficient. Cancer patients generally have lower 25-OHDlevels than healthy controls.

Results from a pilot study at our centre showed a significant reduction in opioid dose for palliative cancer patients treated with cholecalciferol compared to controls.

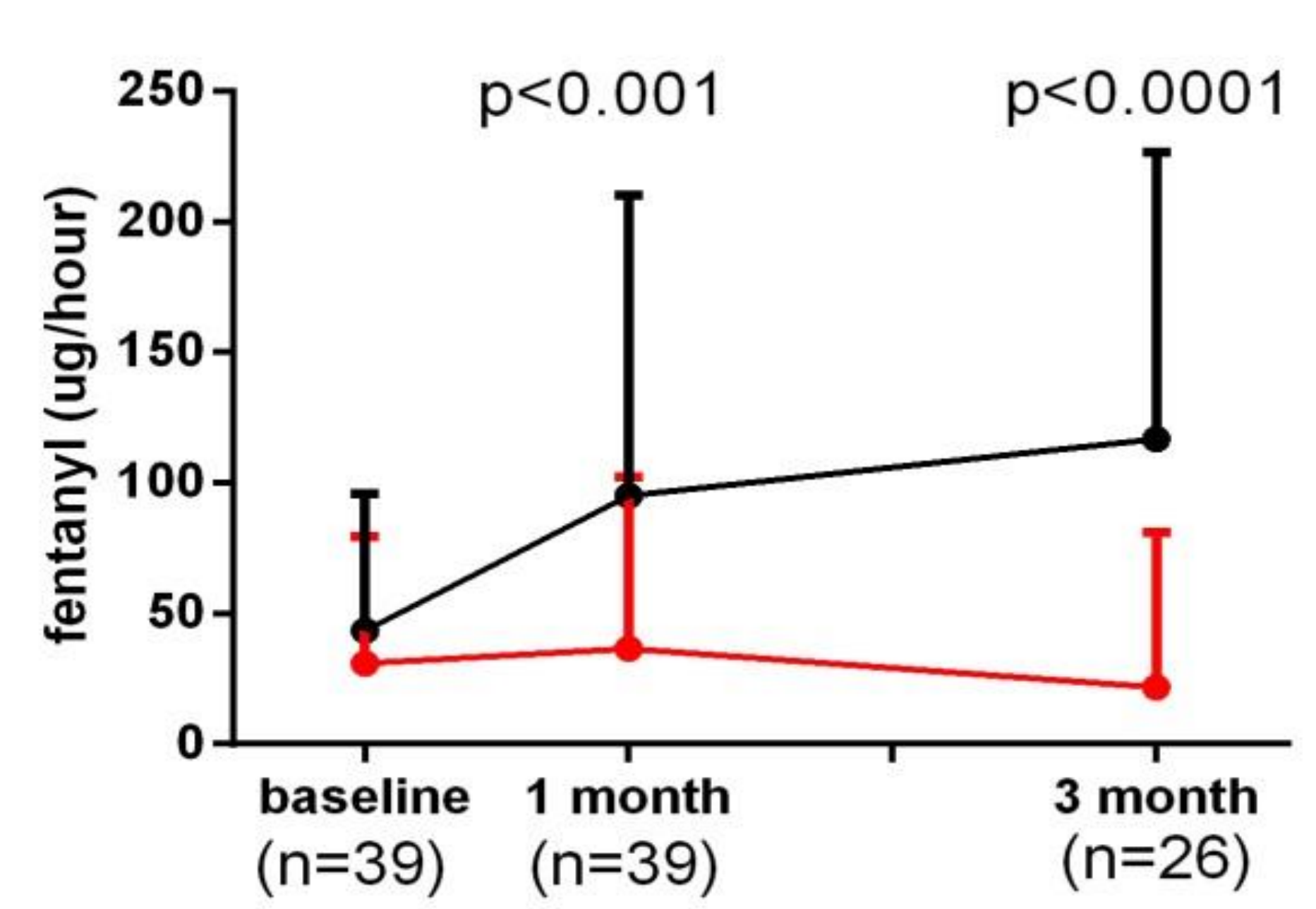

\section{Method}

- A randomized, double blind, placebo controlled multi-centre trial

- 254 palliative cancer patients with $\mathrm{S}-25-\mathrm{OHD}<50 \mathrm{nmol} / \mathrm{L}$, recruited from palliative home care teams

- Intervention: Randomization $1: 1$ to Cholecalciferol 4000 IE/day or placebo for 12 weeks.

- Start Oct 2017, end Dec 2019

\section{Goal}

$n=254$

randomized patients

$n=190$

patients comlete 12 weeks

\section{Data collection}

- Type of cancer, age, sex

- Blood sample for biobank

- S-25-OHD before/after intervention

- S-CRP, S-electrolytes

- Opioid dose

- Antibiotic treatment

- ESAS, EORTC-15-QLQ-PAL
April 2019

$$
n=175
$$

randomized patients

$n=86$

patients completed 12 weeks

$\mathrm{n}=365$

screened patients

\section{Conclusion}

We hope that this RCT will give us sound evidence regarding the use of cholecalciferol in palliative care. At end of study we will have baseline data and biobanked blood samples from more than 500 palliative cancer patients. 